American Journal of Biochemistry and Biotechnology 4(3): 295-303, 2008

ISSN 1553-3468

(C) 2008 Science Publications

\title{
In Vitro Metabolism Studies of Polybrominated Diphenyl Ethers Using Rat and Human Liver Microsomes
}

\author{
Shun Wen Cheng, Kathleen Randall and Anne T. Kotchevar \\ Department of Chemistry and Biochemistry, California State University, \\ East Bay, 25800 Carlos Bee Blvd., Hayward, CA 94542, USA
}

\begin{abstract}
A number of studies have recently reported the bioaccumulation of the commonly used fire retardants, Polybrominated Diphenyl Ethers (PBDEs), in humans and wildlife. Exposure of animals to PBDEs has been shown to result in developmental neurological, reproductive abnormalities and the disruption of endocrine function. Thyroid hormone equilibria was also shown to be altered by PBDE exposure. There is evidence that hydroxylated metabolites of PBDEs are directly involved in some of these adverse effects. Although metabolites of PBDEs have been isolated and characterized during in vivo studies, the identification of metabolites from an in vitro system has been problematic. We investigated the in vitro metabolism of four PBDEs, with varying numbers of bromine atoms, in rat and human liver microsomes. The addition of small amounts of a nonionic surfactant to the reaction mixture was necessary to obtain measurable amounts of metabolites due to the low aqueous solubility of the PBDEs. Using gas chromatography/mass spectroscopy, mono and/or dihydroxylated metabolites were identified from three of the four PBDEs with phenobarbitol- and $\beta$-naphthoflavone-induced rat liver microsomes. When using uninduced rat or human liver microsomes, metabolites were found with only one of the PBDEs. The ease of PBDE metabolism appears to be inversely related to the number of bromine atoms on the parent compound.
\end{abstract}

Key words: PBDE, metabolites, GC-MS, surfactant, solubility

\section{INTRODUCTION}

Polybrominated diphenyl ethers (PBDEs), used as flame retardants in furniture, plastics and electronics, have been identified in lakes, seas and streams around the world ${ }^{[1,2,3,4]}$. Over the past three decades, increasing concentrations of PDBEs have also been found in fish, birds, animals and human plasma and breast milk ${ }^{[5,6,7,8]}$. The predominant PDBE congener found in marine fish, bird and mammal tissues was BDE-47 (2,2',4,4'-tetraBDE), followed by BDE-99 (2,2',4,4',5-penta-BDE) and BDE-100 $\left(2,2^{\prime}, 4,4^{\prime}, 6 \text {-penta-BDE }\right)^{[9]}$. Significant amounts of BDE-153 (2,2',4,4',5,5'-hexa-BDE), BDE$154\left(2,2^{\prime}, 4,4^{\prime}, 5,6^{\prime}\right.$-hexa-BDE) as well as the lower congener BDE-28 (2,4,4'-tri-BDE) have also been found in animal tissues depending on the species ${ }^{[7,10]}$. The reasons for different levels and patterns are largely unknown but may reflect species-related differences in PDBE metabolism and accumulation.

These findings raise concerns because PBDEs have been shown to decrease thyroid hormone levels and cause neurodevelopmental and reproductive defects in animals. Neonatal exposure to several PBDEs resulted in permanent aberration in the spontaneous behaviour of adult mice ${ }^{[11,12]}$. Oral dosing of BDE-99 to pregnant rats resulted in male offspring with pronounced decreases in sex steroids and female offspring with delayed puberty onsets ${ }^{[13]}$. Reduction in serum thyroid hormones has been reported in young rats following a 4-day exposure to commercial PBDE mixtures ${ }^{[14]}$. There is evidence that hydroxylated metabolites of PBDEs are responsible for the disruption to thyroid hormone equilibria. PBDEs exposed to microsomes were able to compete with thyroxine for binding to the thyroid transport hormone transthyretin with a much greater affinity than untreated di-, tri-, tetra- and pentaBDEs $^{[15]}$. Several synthesized hydroxylated PBDEs have also been shown to bind better to the thyroid receptor than their unhydroxylated counterparts ${ }^{[16]}$. In addition, using an in vitro assay measuring the combined activities of $17 \quad \alpha$-hydroxylase and 17,20-lyase, 6-OH-BDE-47 was found to strongly inhibit the activity of CYP17, an enzyme involved in sex hormone biosynthesis, whereas the parent compound, BDE-47, did not inhibit the activity $^{[17]}$.

Corresponding Author: Dr. Anne T. Kotchevar, Department of Chemistry and Biochemistry, California State University, East Bay, 25800 Carlos Bee Blvd., Hayward, CA, USA Tel: 510-885-3478 Fax: 510-885-4675 
In vitro metabolism studies using liver microsomes from marine mammals found no detectable depletion of a Bromkal 70 mixture of PBDE (BDE-47 and BDE99) ${ }^{[18]}$. However, it is possible that the rate of microsomal metabolism was too slow to observe on the timescale used or that the concentration of PBDE was too high to measure a significant depletion. An in vitro metabolism study comparing the depletion of a mixture of PBDEs by liver microsomes isolated from whale and rat demonstrated decreases in the PBDE concentrations after $90 \min ^{[19]}$. The amount of PBDE metabolized varied with the number and location of bromine atoms on the PBDE. Despite significant depletion of the PBDEs with the whale liver microsomes, only a single phenolic metabolite (from BDE-15) was observed. Harju et al. also saw depletion of PBDEs in an in vitro metabolism assay using rat liver microsomes obtained from rats pretreated with phenolbarbital ${ }^{[20]}$. The degradation half-life of the tested PBDEs was dependent on both the number of bromine atoms and their substitution pattern on the phenyl rings. In these studies, however, the microsomal metabolites of the PBDEs were not isolated or characterized.

PBDEs are metabolized to hydroxylated metabolites as demonstrated in several in vivo studies. In rats and mice, after oral doses of ${ }^{14} \mathrm{C}$-labelled BDE47, small amounts of five monohydroxylated metabolites were detected in the feces and tissues ${ }^{[21]}$. These metabolites were tentatively assigned to be two ortho-OH-tetra-BDE, one meta-OH-tetra-BDE and two para-OH-tetra-BDE metabolites. In an analysis of the blood plasma of BDE-47-exposed rats, sixteen $\mathrm{OH}-$ PBDEs and two di-OH PBDEs were detected ${ }^{[22]}$. Four of the metabolites were identified as 3-OH-tetra-BDE, 4-OH-tetra-BDE, 4'-OH-tetra-BDE and 6-OH-tetraBDE. Oxidative debromination was also found to be a metabolic pathway. After oral administration of BDE47, a tetra-BDE, to rats six OH-tetra-BDEs and three $\mathrm{OH}$-tri-BDEs metabolites were isolated and structurally identified from their feces ${ }^{[23]}$. Following an oral dose of BDE-99, a penta-BDE, to male rats, trace amounts of two mono-OH-penta-BDE and two debrominated mono-OH-tetra-BDE metabolites were detected in the feces ${ }^{[24]}$. Other studies on the metabolism of BDE-99 in rats and mice using ${ }^{14} \mathrm{C}$-labelled BDE-99 identified mono-OH-penta-BDEs and mono-OH-tetra-BDEs as metabolites, as well as glutathione and glucuronide conjugates of some of the hydroxylated $\mathrm{BDEs}^{[25]}$. A study in rats of the metabolism of BDE-100, a pentaBDE congener, found evidence of five mono-OH-penta BDEs, six mono-OH-tetra BDEs and two di-OH-tetraBDEs metabolites ${ }^{[26]}$. Debromination of BDE-99 to BDE-47 without hydroxylation was seen in studies
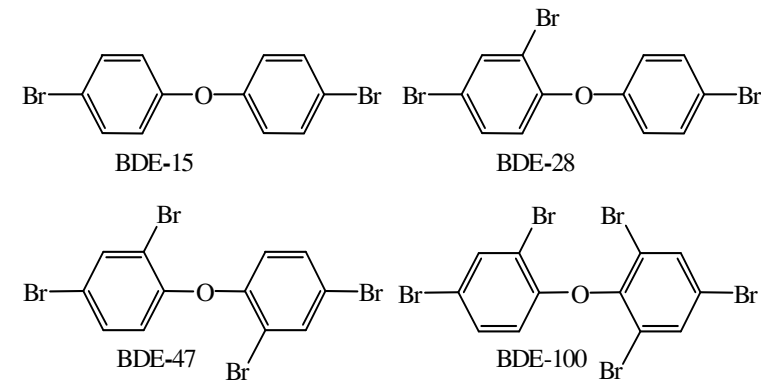

Fig. 1: Structures of the four PBDEs used in this study

using intestine and liver microsomes obtained from carp $^{[27]}$. However, because the presence of NADH in the assay did not affect the degree of debromination, it is unlikely to be the result of cytochrome P450 activity.

Understanding the process by which xenobiotics such as PBDEs are broken down in the body is important in determining the risks of chemical exposure and is a critical consideration in the regulation of chemicals. Development of an in vitro system to study the metabolism of PBDE would facilitate the elucidation of its metabolic pathways. In the present study we investigated the in vitro metabolism of four PBDEs using rat and human liver microsomes. Our aim was to identify the products of metabolism and to determine the effect of the number of bromine substituents in the starting compound on the ease of metabolism. Since the commercially available PBDE flame retardants are generally sold as technical mixtures, we synthesized four pure PBDEs (Fig. 1). We chose 4,4'-dibromodiphenyl ether (BDE-15), 2,4,4'tribromodiphenyl ether (BDE-28), 2,2'4,4'tetrabromodiphenyl ether (BDE-47) and 2,2'4,4',6pentabromodiphenyl ether (BDE-100) as they are among the more prevalent congeners found in the environment and in order to investigate PBDEs with varying numbers of bromine atoms in the ortho and para positions.

\section{MATERIALS AND METHODS}

Chemicals and microsomes: The PBDEs were synthesized according to published procedures ${ }^{[16,28]}$ and determined to be greater than $99.9 \%$ pure by ${ }^{1} \mathrm{H}$ NMR and gas chromatography and mass spectroscopy. Tween 20 and diphenyl ether were purchased from Aldrich Chemical Company Inc. (Milwaukee, WI) and used as supplied. Solvents and $\mathrm{NaCl}$ were from Fisher Scientific (Fair Lawn, NJ). NADPH, Tris salt and N,Obis(trimethylsilyl) trifluoroacetamide (BSTFA) were obtained from Sigma Chemical Company (St. Louis, 
MO). Human liver microsomes, male Sprague-Dawley rat liver microsomes and phenolbarbitol- and $\beta$ naphthoflavone-induced male Sprague-Dawley rat liver microsomes were obtained from Xenotech, LLC (Kansas City, MO). The rats had been dosed with 100 $\mathrm{mg} \beta$-naphthoflavone $/ \mathrm{kg}$ body weight and $80 \mathrm{mg}$ phenobarbitol/kg body weight on days 1-4 with the liver microsomes prepared on day 5 .

Instrumentation: ${ }^{1} \mathrm{H}$ NMR spectra of the synthesized PBDEs were obtained using a Varian Inova $400 \mathrm{MHz}$ spectrometer relative to internal trimethylsilane in deuterated chloroform. HPLC was performed on an Agilent, Model HP 1100 series with a reverse phase column (Zorbax Eclipse-XDB-C18; Phenomenex, Torrance, CA). The mobile phase was a mixture of $80 \%$ $\mathrm{CH}_{3} \mathrm{CN}$ and $20 \%$ water which contained $0.05 \%$ trifluoracetic acid and $0.05 \%$ triethylamine and the flow rate was $1.0 \mathrm{~mL} \mathrm{~min}$. The wavelength was set at $250 \mathrm{~nm}$ for detection with a reference of $420 \mathrm{~nm}$. Gas Chromatography/Mass Spectroscopy (GC-MS) was performed on a Varian CP3800 gas chromatograph and Varian Saturn 2000 mass spectrometer. The gas chromatograph was equipped with a DB-8 fused silica capillary column, $9.3 \mathrm{~m} \times 0.25 \mathrm{~mm}, 0.25 \mu \mathrm{m}$ film thickness. The temperature of the injector was set at $280^{\circ} \mathrm{C}$ and the flow-rate was maintained at $1.2 \mathrm{~mL} \mathrm{~min}{ }^{-1}$ using helium as the carrier gas. The temperature program for PBDE metabolite studies was as follows: the initial temperature was set at $100^{\circ} \mathrm{C}$, held for $3 \mathrm{~min}$, ramped at $15^{\circ} \mathrm{C} \mathrm{min}^{-1}$ to $220^{\circ} \mathrm{C}$ where it was held for $8 \mathrm{~min}$, ramped at $8^{\circ} \mathrm{C} \mathrm{min}^{-1}$ to $280^{\circ} \mathrm{C}$ where it was held for $8 \mathrm{~min}$, ramped at $30^{\circ} \mathrm{C} \mathrm{min}$ to $300^{\circ} \mathrm{C}$ and held for $2 \mathrm{~min}$. The temperature program for the 7-ethoxycoumarin studies was $80^{\circ} \mathrm{C}$ initial temperature for $0.5 \mathrm{~min}$, ramped at $20^{\circ} \mathrm{C} \mathrm{min}{ }^{-1}$ to $120^{\circ} \mathrm{C}$, held for $1 \mathrm{~min}$, ramped $9^{\circ} \mathrm{C} \mathrm{m^{-1 }}$ to $180^{\circ} \mathrm{C}$, held for $2 \mathrm{~min}$, ramped $30^{\circ} \mathrm{C} \mathrm{min}^{-1}$ to $220^{\circ} \mathrm{C}$, held for $2 \mathrm{~min}$, ramped $40^{\circ} \mathrm{C} \mathrm{min}^{-1}$ to $300^{\circ} \mathrm{C}$ and held for $4.5 \mathrm{~min}$. The mass-selective detector was used in the electron impact mode $(70 \mathrm{eV})$ at low resolution.

PBDE solubility determination: Each PBDE was added to $0.06 \%$ Tween $20(\mathrm{w} / \mathrm{v})$ in Tris buffer $(100 \mathrm{mM}$ Tris, $5 \mathrm{mM} \mathrm{MgCl}_{2}, \mathrm{pH} 7.4$ ) at $0.5 \mathrm{mg} \mathrm{mL}^{-1}$. The samples were sonicated in a water bath sonicator for $30 \mathrm{~min}$ at room temperature and then filtered through a $0.45 \mu \mathrm{m}, 13 \mathrm{~mm}$ syringe filter (Fisherbrand, Fisher Scientific, Fair Lawn, NJ). The filtrate was quantified for the PBDE by HPLC using a calibration curve generated with the PBDE dissolved in acetonitrile (100\% solubility). All samples were assayed in triplicate.

PBDE in vitro metabolism studies: Incubation of the liver microsomes (from untreated rat, phenobarbital- and $\beta$-naphthaflavone-induced rat, or human) and PBDE were carried out in duplicate in a $12 \mathrm{~mL}$ test tube using a shaking water bath at $37^{\circ} \mathrm{C}$. A typical incubation mixture consisted of $390 \mu \mathrm{L} 0.06 \%$ Tween $20(\mathrm{w} / \mathrm{v})$ in Tris buffer (see composition above), $200 \mu \mathrm{L}$ microsome solution $\left(20 \mathrm{mg}\right.$ protein $\left.\mathrm{mL}^{-1}\right)$ and $10 \mu \mathrm{L}$ PBDE (0.1 $\mathrm{M}$ in acetonitrile). After bringing the test tube to temperature, the reaction was initiated by the addition of $400 \mu \mathrm{L}$ NADPH (15 mM in Tris buffer). The test tube was covered with aluminum foil to shield from the light before the addition of NADPH and additional aluminum foil with holes was used as lid to allow sufficient oxygen supply into the reaction. The metabolism reactions were incubated for $20 \mathrm{~h}$ at $37^{\circ} \mathrm{C}$. Longer times were found to be unproductive as the microsomes were no longer viable.

After $20 \mathrm{~h}$, the reaction was terminated by the addition of $600 \mathrm{mg} \mathrm{NaCl}$ and $1 \mathrm{~mL}$ ethyl acetate containing $1 \mathrm{mM}$ diphenyl ether as an extraction internal standard. The precipitated protein was pelleted using a centrifuge. The sample was extracted with an equal volume of ethyl acetate three times. The ethyl acetate fractions were combined and dried over sodium sulfate and the solvent removed with a stream of nitrogen. The dried sample was redissolved in $100 \mu \mathrm{L}$ ethyl acetate and all hydroxyl groups were transformed into trimethylsilyl derivatives by addition of $10 \mu \mathrm{L}$ BSTFA to ensure volatility for GC-MS analysis. The sample was analyzed for metabolites by GC-MS, operating in full scan mode. Satisfactory separation of the PBDE parent compound, its metabolites and the organic soluble components of the microsomes was achieved using the GC conditions as described. New GC peaks were identified by comparison of the spectra with two control reactions; the system without the addition of NADPH and the system without the addition of PBDE. No metabolites were detected when incubations were performed in the absence of NADPH, nor in the absence of the PBDE. Therefore, all the metabolites identified were products of microsomalmediated reactions. The peak areas of the metabolites were measured in Mcounts $\mathrm{x}$ min where Mcounts are $1 \times 10^{6}$ mass counts $/ \mathrm{sec}$ and are reported as the ratio of the area of the metabolite to the area of the diphenyl ether (DPE) extraction standard.

7-Ethoxycoumarin in vitro metabolism studies: The conversion of 7-ethoxycoumarin to 7-hydroxycoumarin is commonly used as a measure of CYP activity ${ }^{[29]}$ and was used here to compare the activity of the different microsomal preparations and the activity of the microsomes in the presence and absence of Tween 20. The experiments were conducted as above for the 
PBDE metabolism studies with $20 \mathrm{mM}$ 7ethoxycoumarin, $10 \mu \mathrm{L}$ microsomal solution $(20 \mathrm{mg}$ protein $\mathrm{mL}^{-1}$ ) and $20 \mu \mathrm{L}$ NADPH $(15 \mathrm{mM}$ in Tris buffer). The time of reaction was $2 \mathrm{~h}$.

\section{RESULTS}

The difference in the activity of the different microsomal preparations (untreated rat, induced rat and human) was noted when the standard 7-ethoxycoumarin metabolism reaction was analyzed. The amount of 7ethoxycoumarin remaining in the reaction mixture after the microsomal reaction was compared to the amount in the control reaction (no NADPH, time $=0 \mathrm{~h}$ ). With untreated rat microsomes, there was a $15.5 \%$ decrease in the amount of 7-ethoxycoumarin after $2 \mathrm{~h}$; with the same amount and time of induced microsomes there was a $39.2 \%$ decrease; and with human microsomes there was a $5.5 \%$ decrease. A nonionic surfactant, Tween 20, was used in the PBDE in vitro metabolism reactions at a final concentration of $0.06 \%$ because of the low water solubility of the PBDEs. Attempts to run the reactions without the presence of a surfactant resulted in no detectable formation of metabolites. Experiments using the conversion of 7-ethoxycoumarin to 7-hydroxycoumarin as a measure of CYP activity determined that at this concentration of Tween 20, CYP activity was roughly halved. This corresponds well to data obtained on the structurally similar Tween 80 which showed a decrease in ethoxyresorufin-Odeethylase (EROD) activity of about half at a $0.065 \%$ concentration $^{[30]}$. The aqueous solubility of the PBDEs in the Tris buffer solution with $0.06 \%$ Tween 20 was determined to be $397 \mu \mathrm{M}$ for BDE-15, $196 \mu \mathrm{M}$ for BDE-28, $64 \mu \mathrm{M}$ for BDE-47 and $35 \mu \mathrm{M}$ for BDE-100.

Eight metabolites were found in the gas chromatograms of BDE-15 microsomal reactions with uninduced and induced rat microsomes (Fig. 2). Retention times $\left(t_{R}\right)$, mass spectral data and ratio of the peak areas of the trimethylsilyl derivatives of the metabolites (M) to the extraction standard DPE (diphenyl ether) are given in Table 1. The amount of metabolites formed was extremely small in comparison to the remaining BDE-15 after reaction indicating that CYP oxidation reactions of PBDEs are not readily accomplished by microsomal enzymes. Remaining BDE-15 typically had a peak area on the order of 15.0 Mcounts $\mathrm{x}$ min compared to the 0.4 Mcounts $\mathrm{x}$ min area of the largest metabolite. Two of the metabolites, with retention times 9.7 and $10.1 \mathrm{~min}$, appear to be isomers of a mono-OH-mono-BDE. Three

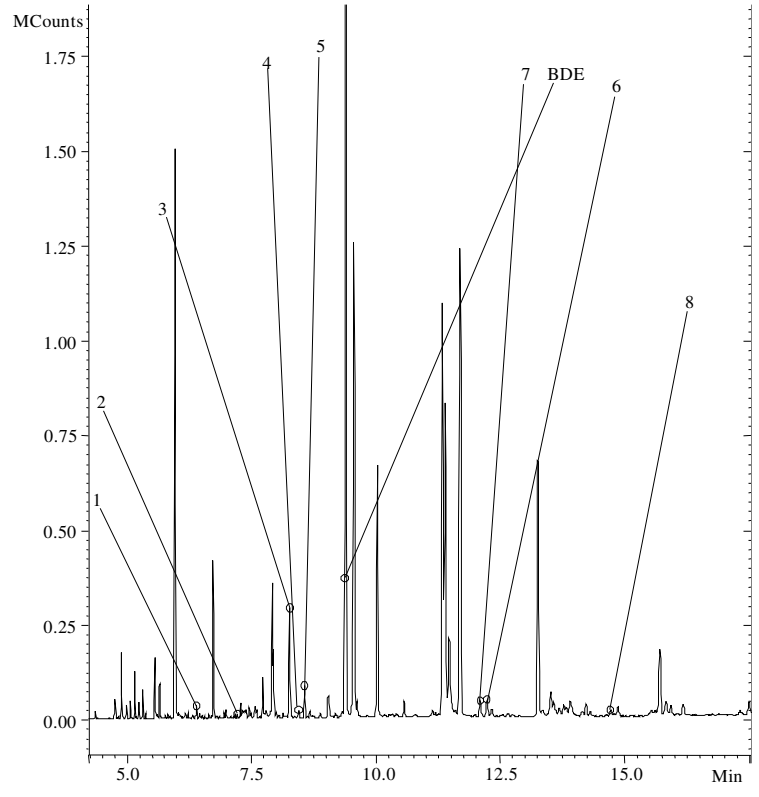

Fig. 2: Total ion gas chromatogram of the reaction of BDE-15 with induced rat microsomes after derivatization with BSTFA. Peaks 1-2 correspond to the mono-OH-mono-BDE metabolites, peaks 3-5 correspond to the di-OHdiphenyl ether metabolites and peaks 6-8 correspond to the mono-OH-di-BDE metabolites. The unlabeled peaks correspond to the organic soluble components of the microsomes

of the metabolites, with retention times of $12.2,12.3$ and $13.0 \mathrm{~min}$, have mass spectra consistent with the trimethylsilyl derivative of a dihydroxylated diphenyl ether. The remaining three, with retention times of 16.0, 16.1 and $18.1 \mathrm{~min}$, are consistent with the derivatized mono-OH-di-BDE isomers. The ratio of the peak area of the metabolites to the extraction standard in reactions with induced rat microsomes was greater for most metabolites than in reactions with uninduced rat microsomes. Using the human microsomes, only three of the metabolites were seen, viz. the three isomers of the dihydroxylated diphenyl ethers and the ratio of their areas to the extraction standards were considerably less. Their retention times $(12.2,12.3$ and $13.0 \mathrm{~min})$ and mass spectra matched those produced with rat microsomes.

Two metabolites were observed in the reaction of BDE-28 with induced rat microsomes as shown in Table 2. The peak area of the remaining BDE-28 was 
Table 1: GC-MS data and proposed structures of BDE-15 metabolites (M) from induced and uninduced rat and human liver microsomes after derivatization with BSTFA. N.D. = not detected

\begin{tabular}{|c|c|c|c|c|c|c|}
\hline Peak & $t_{R}(\min )$ & EIMS m/z [ion] & $\begin{array}{l}\text { Ratio area M/DPE } \\
\text { induced rat }\end{array}$ & $\begin{array}{l}\text { Ratio area M/DPE } \\
\text { uninduced rat }\end{array}$ & $\begin{array}{l}\text { Ratio area } \\
\text { M/DPE human }\end{array}$ & Metabolite \\
\hline 1 & 9.7 & $336\left[\mathrm{M}^{+}\right] 321\left[\left(\mathrm{M}-\mathrm{CH}_{3}\right)^{+}\right]$ & 0.37 & 0.11 & N.D. & Mono-OH-mono-BDE \\
\hline 2 & 10.1 & $336\left[\mathrm{M}^{+}\right] 321\left[\left(\mathrm{M}-\mathrm{CH}_{3}\right)^{+}\right]$ & 0.24 & 0.31 & N.D. & Mono-OH-mono-BDE \\
\hline 3 & 12.2 & $346\left[\mathrm{M}^{+}\right] 331\left[\left(\mathrm{M}-\mathrm{CH}_{3}\right)^{+}\right]$ & 4.46 & 1.25 & 0.14 & Di-OH-diphenyl ether \\
\hline 4 & 12.3 & $346\left[\mathrm{M}^{+}\right] 331\left[\left(\mathrm{M}-\mathrm{CH}_{3}\right)^{+}\right]$ & 0.31 & 0.60 & 0.06 & Di-OH-diphenyl ether \\
\hline 5 & 13.0 & $346\left[\left(\mathrm{M}^{+}\right] 331\left[\left(\mathrm{M}-\mathrm{CH}_{3}\right)^{+}\right]\right.$ & 1.27 & 0.34 & 0.09 & Di-OH-diphenyl ether \\
\hline 6 & 16.0 & $416\left[(\mathrm{M}+2)^{+}\right] 401\left[\left(\mathrm{M}-\mathrm{CH}_{3}+2\right)^{+}\right]$ & 1.04 & 0.30 & N.D. & Mono-OH-di-BDE \\
\hline 7 & 16.1 & $416\left[(\mathrm{M}+2)^{+}\right] 401\left[\left(\mathrm{M}-\mathrm{CH}_{3}+2\right)^{+}\right]$ & 1.05 & 0.01 & N.D. & Mono-OH-di-BDE \\
\hline 8 & 18.1 & $416\left[(\mathrm{M}+2)^{+}\right] 401\left[\left(\mathrm{M}-\mathrm{CH}_{3}+2\right)^{+}\right]$ & 0.50 & 0.54 & N.D. & Mono-OH-di-BDE \\
\hline
\end{tabular}

Table 2: GC-MS data and proposed structures of BDE-28 metabolites (M) from induced rat liver microsomes after derivatization with BSTFA

\begin{tabular}{|c|c|c|c|c|}
\hline Peak & $\mathrm{t}_{\mathrm{R}}(\min )$ & $\begin{array}{l}\text { EIMS } \\
\mathrm{m} / \mathrm{z} \text { [ion] }\end{array}$ & $\begin{array}{l}\text { Ratio area } \\
\text { M/DPE }\end{array}$ & Metabolite \\
\hline 1 & 21.1 & $\begin{array}{l}494\left[(\mathrm{M}+2)^{+}\right] \\
479\left[\left(\mathrm{M}-\mathrm{CH}_{3}+2\right)^{+}\right]\end{array}$ & 0.38 & $\begin{array}{l}\text { Mono-OH- } \\
\text { tri-BDE }\end{array}$ \\
\hline 2 & 23.0 & $\begin{array}{l}584\left[(\mathrm{M}+4)^{+}\right] \\
570\left[\left(\mathrm{M}-\mathrm{CH}_{3}+4\right)^{+}\right]\end{array}$ & 0.62 & $\begin{array}{l}\text { Di-OH- } \\
\text { tri-BDE }\end{array}$ \\
\hline
\end{tabular}

Table 3: GC-MS data and proposed structure of BDE-47 metabolite (M) from induced rat liver microsomes after derivatization with BSTFA

\begin{tabular}{lllll}
\hline & & & Ratio area & \\
Peak & $\mathrm{t}_{\mathrm{R}}(\mathrm{min})$ & EIMS m/z [ion $]$ & $\mathrm{M} / \mathrm{DPE}$ & Metabolite \\
\hline 1 & 25.3 & $574\left[(\mathrm{M}+4)^{+}\right] 478$ & 0.70 & Mono-OH- \\
& & {$\left[\left(\mathrm{M}-\mathrm{Br}-\mathrm{CH}_{3}+2\right)^{+}\right]$} & & tetra-BDE \\
& & $414\left[(\mathrm{M}-2 \mathrm{Br}+2)^{+}\right]$ & & \\
\hline
\end{tabular}

more than 200 times the area of the sum of the metabolite peaks indicating that the reaction proceeds to a very small extent. No metabolites were found under the same conditions with either uninduced rat or human liver microsomes. Ratios of peak areas and mass spectral data for the two metabolites, as the trimethylsilyl derivatives, are given in Table 2 . According to the mass spectra, the metabolite with the retention time of $21.1 \mathrm{~min}$ corresponds to a mono-OHtri-BDE. The peak at $23.0 \mathrm{~min}$ is consistent with a di$\mathrm{OH}$-tri-BDE.

Only one metabolite was found when BDE-47 was reacted with induced rat microsomes as shown in Table 3. As with the previous PBDEs, the amount of BDE-47 converted to metabolite was very small, the peak area of BDE-47 remaining after reaction was more than 300 times the peak area of the metabolite. The mass spectrum of the metabolite, which had a retention time of $25.3 \mathrm{~min}$, was consistent with a mono-OH-tetraBDE (Table 3). No debrominated metabolites were detected in the in vitro microsomal reactions with BDE47 or BDE-28. As in the microsomal reactions with
BDE-28, reaction of BDE-47 with uninduced rat or human liver microsomes produced no measurable metabolites. With BDE-100, no metabolites were observed after reaction with induced or uninduced rat, or human liver microsomes under the same conditions as reaction with the other PBDEs.

\section{DISCUSSION}

In vitro metabolism of $\mathrm{BDE}-15$ with rat microsomes formed mono-OH-di-BDEs, mono-OHmono-BDEs and di-OH-diphenyl ethers. The latter two types of isomers involved not only oxidation but loss of one or more bromine substituents. Oxidative debromination of some PBDEs has been reported to occur in several in vivo studies ${ }^{[23,24,25,26]}$. Although ipso substitution of a hydroxyl group for a halogen has been seen in phenolic compounds it is not likely the only operative oxidative mechanism here for the formation of the monobrominated, monohydroxylated or dihydroxylated diphenyl ethers as more than one isomer of each metabolite was observed. In order to obtain these isomers, hydroxylation must occur in different positions on the rings and not only as a replacement for the bromine in the para position. Three isomers were also detected for the monohydroxylated BDE-15 metabolites suggesting that at least one of them involves an NIH-shift of the bromine on the ring through an arene oxide.

When pooled human microsomes were used with BDE-15, three of the rat metabolites were found corresponding to the debrominated and dihydroxylated BDE isomers (compounds 3 - 5, Table 1). The relative amounts of the three isomers varied depending on whether the reaction was conducted with rat or human microsomes. Differences in the metabolic capacities of 
cytochrome P450s in various species are known to lead to variable responses from different organisms toward the same chemical ${ }^{[31]}$. However, this difference may mean that studies conducted in animals on PBDE metabolism may be misleading in predicting human health hazards.

Mono and dihydroxylated metabolites were obtained from the in vitro metabolism reaction of BDE-28 with rat microsomes in which CYP1A and CYP2B had been induced. Commercial PDBE mixtures and some individual congeners have been shown to be capable of inducing the cytochrome P450 enzymes CYP1A and CYP2B ${ }^{[11,32]}$. The requirement for induced rat microsomes and the appearance of fewer metabolites indicates an inherent difficulty in the metabolism of PBDE with additional bromine substituents. A comparison of the peak areas of the two metabolites determined that the amount of dihydroxylated BDE-28 was consistently higher than monohydroxylated BDE-28. This suggests that the initial hydroxylation is the slower step in BDE-28 metabolism and that once the monohydroxylated metabolite is formed, it is more readily converted to the dihydroxylated compound. Harju et al. observed the in vitro microsomal depletion half-life of 6-OH-2,2'4,4'BDE was more than ten times shorter than its nonhydroxylated analog BDE-47 ${ }^{[20]}$.

A single mono-OH-tetra-BDE was found in the reaction of BDE-47 with induced rat microsomes. Reports of in vivo studies with BDE-47 also identified mono-OH tetra BDEs as being the major metabolites, although several isomers were seen ${ }^{[21,22,23]}$. The amount of metabolite produced in our in vitro study was small relative to the parent compound so it is possible that other isomers may have been lower than our detection limit. As in the case with BDE-28, no metabolites were seen after in vitro microsomal reactions with uninduced rat or human microsomes. No metabolites were seen from the pentabrominated diphenyl ether (BDE-100) even with the induced microsomes although pentabrominated diphenyl ethers have been shown to form metabolites during in vivo studies ${ }^{[24,25,26]}$. It is possible that the formation of metabolites from BDE100 required a longer period than our time scale allowed.
It appears then that the presence of more bromine substituents decreases the ease in which microsomal oxidation can occur. It may be that increasing the number of bromine substituents hinders the ability of the cytochrome P450 enzymes to oxidize and, in some cases, debrominate the substrate. This is in contrast to studies of photochemical debromination of PBDEs in which the rate of decomposition decreased with decreasing numbers of bromine substituents ${ }^{[33]}$. In a study comparing in vitro metabolism of PBDEs using rat and whale liver microsomes, McKinney et al. found there were species specific differences in the ability to metabolize individual PBDEs ${ }^{[19]}$. The whale liver microsomes readily depleted BDE-15 and to lesser extents BDE-28 and BDE-47. On the other hand, no depletion of BDE-15 and BDE-47 were seen with the rat microsomes. BDE-28 was depleted to some extent but the most depletion with the rat microsomes occurred with BDE-49 (2,2'4,5'-tetra-BDE) and BDE99 (2,2'4,4',5-penta-BDE). In the in vitro microsomal depletion studies using induced rat liver microsomes conducted by Harju et al., a comparison of depletion half-lives showed that the molecular size of PBDEs is a reaction rate-determining property, but the metabolism of PBDEs also increased with vicinal hydrogens in the meta-para position ${ }^{[20]}$. The compounds in the present study have at least one pair of hydrogens in the orthometa position and no pairs in the meta-para position. Within this series, where the positions of the bromine atoms are limited to the ortho and para positions, ease of metabolism does appear to correlate inversely with the molecular size.

The octanol-water partition coefficients $\left(\mathrm{K}_{\mathrm{ow}}\right)$ of PBDEs have been demonstrated to increase with increasing bromine content ${ }^{[34]}$. In our system, the number of metabolites produced and the amount of metabolites isolated from the microsomal system also correlates with the water solubility of the PBDE. It may be that the solubility of the compound plays a role in the ease of metabolism and that the greater solubility of the lower brominated congeners facilitates enzymesubstrate interactions. Other lipophilic substrates have been shown to be metabolized in the absence of added solvent through interaction with microsomes as fast or faster than in the presence of solvent ${ }^{[35]}$. In our study 
however, no metabolites were detected after reaction without the presence of the surfactant.

In summary, this study has developed an in vitro system to study the biotransformation of three polybrominated diphenyl ethers in rat and human liver microsomes. Solubilization of the PBDE in the aqueous microsomal system was found to be necessary for reaction to occur and was accomplished by the use of the nonionic detergent Tween 20. There were considerable differences in the quantity and kind of metabolites formed from the PBDE cogeners studied. The in vitro microsomal oxidation reactions were hindered with greater numbers of bromine substituents on the PBDE. Metabolites were formed from the dibromodiphenyl ether in the in vitro metabolism reaction both in the induced and uninduced microsomal system. However, in order to obtain measurable metabolites from PBDEs with more than two bromines, it was necessary to use microsomes from rats in which CYP1A and CYP2B had been induced through treatment with phenobarbital and $\beta$-naphthoflavone.

\section{ACKNOWLEDGMENTS}

We thank Dr. Becky Gee, Long Island University, Brooklyn, NY, for the NMR characterization of the synthesized polybrominated diphenyl ethers and Mr. Jim Stanford, California State University East Bay, Hayward, CA for his assistance with the GC-MS. This work was supported by a CSU Program for Education and Research in Biotechnology (CSUPERB) Faculty Seed Grant to A.T.K.

\section{REFERENCES}

1. Kolpin, D.W., E.T. Furlong, M.T. Meyer, E.M. Thurman, S.D. Zaugg, L.B. Barber and H.T. Buxton, 2002. Pharmaceutical, hormones and other organic wastewater contminants in US streams, 1999-2000: A national reconnaissance. Environ. Sci. Technol., 36: 1202-1211.

2. Vorkamp, K., J.H. Christiansen and F. Riget, 2004. Polybrominated diphenyl ethers and organochlorine compounds in biota from the marine environment of East Greenland. Sci. Total Environ., 331: 143-155.
3. Oros, D.R., D. Hoove, F. Rodigari, D. Crane and J. Sericano, 2005. Levels and distribution of polybrominated diphenyl ethers in water, surface sediments and bivalves from the San Francisco Estuary. Environ. Sci. Technol., 39: 33-41.

4. Evenset, A., G.N. Christensen, J. Carroll, A. Zaborska, U. Berger, D, Herzke and D. Gregor, 2007. Historical trends in persistent organic pollutants and metals recorded in sediment from Lake Ellasjoen, Bjornoya, Norwegian Arctic. Environ. Pollut., 146: 196-205.

5. Meironyte, D., K. Noren and A. Bergman, 1999. Analysis of polybrominated diphenyl ethers in Swedish human milk. A time-related study, 19721997. J. Toxicol. Environ. Health, 58: 329-341.

6. de Wit, C.A., 2002. An overview of brominated flame retardants in the environment. Chemosphere, 46: 583-624.

7. Wolkers, H., B. Van Bavel, A.E. Derocher, O. Wiig, K.M. Kovacs, C. Lydersen and G. Lindstrom, 2004. Congener-specific accumulation and food chain transfer of polybrominated diphenyl ethers in two Arctic food chains. Environ. Sci. Technol., 38: 1667-1674.

8. Schecter, A., O. Papke, K.C. Tung, J. Joseph, T.R. Harris and J. Dahlgren, 2005. Polybrominated diphenyl ether flame retardants in the US population: Current level, temporal trends and comparisons with dioxins, dibenzofurans and polychlorinated biphenyls. J. Occup. Environ. Med., 47: 199-211.

9. Martin, M., P.K.S. Lam and B.J. Richardson, 2004. An Asian quandary: Where have all the PBDEs gone? Mar. Pollut. Bull., 49: 375-382.

10. de Boer, J., K. de Boer and J.P. Boon, 2000. Polybrominated biphenyls and diphenyl ethers. In: The Handbook of Environmental Chemistry. J. Paasivirta (Ed.) Springer, Berlin, 3: 61-95..

11. Viberg, H., A. Frediksson and P. Eriksson, 2003. Neonatal exposure to polybromodiphenyl ether (PBDE-153) disrupts spontaneous behaviour, impairs learning and memory and decreased hippocampal cholinergic receptors in adult mice. Toxicol. Appl. Pharmacol., 192: 95-106. 
12. Viberg, H., A. Frediksson and P. Eriksson, 2005. Deranged spontaneous behaviour and decrease in cholinergic muscarinic receptors in hippocampus in the adult rat, after neonatal exposure to the brominated flame-retardant, 2,2'4,4',5pentabromodiphenyl ether (PBDE99). Environ. Toxicol. Pharmacol., 20: 283-288.

13. Lillienthal, H., A. Hack, A. Roth-Harer, S.W. Grande and C.E. Talsness, 2006. Effects of developmental exposure to 2,2'4,4'5pentabromodiphenyl ether (PBDE-99) on sex steroids, sexual development and sexually dimorphic behavious in rats. Environ. Health Persp., 114: 194-201.

14. Zhou, T., D.G. Ross, M.J. DeVito and K.M. Crofton, 2001. Effects of short-term in vivo exposure to polybrominated diphenyl ethers on thyroid hormones and hepatic enzyme activities in weanling rats. Toxicol. Sci., 61: 76-82.

15. Meerts, I.A.M., J.J. van Zanden, E.A.C. Lujiks, I. van Leeuwen-Bol, G. Marsh, E. Jakobsson, A. Bergman and A. Brouwer, 2000. Potent competitive interactions of some brominated flame retardants and related compounds with human transthyretin in vitro. Toxicol. Sci., 56: 95-104.

16. Marsh, G., J. Hu, E. Jakobsson, S. Rahm and A. Bergman, 1999. Synthesis and characterization of 32 polybrominated diphenyl ethers. Environ. Sci. Technol., 33: 3033-3037.

17. Canton, R.F., J.T. Sanderson, S. Nijmeijer, A. Bergman, R.L. Lechter and M. van der Berg, 2006. In vitro effects of brominated flame retardants and metabolites on CYP17 catalytic activity: a novel mechanism of action? Toxicol. Appl. Pharmacol., 216: 274-281.

18. Hakk, H. and R.J. Letcher, 2003. Metabolism in the toxicokinetics and fate of brominated flame retardants-a review. Environ. Int., 29: 801-828.

19. McKinney, M.A., S. De Guise, D. Martineau, P. Beland, A. Arukwe and R.J. Letcher, 2006. Biotransformation of polybrominated diphenyl ethers and polychlorinated biphenyls in beluga whale (Delphinapterus leucas) and rat mammalian model using an in vitro hepatic microsomal assay. Aquat. Toxicol., 66: 87-97.
20. Harju, M., T. Hamers, J.H. Kamstra, E. Sonneveld, J.P. Boon, M. Tysklind and P.L. Anderssen, 2007. Quantitative structure-activity relationship modeling on in vitro endocrine effects and metabolic stability involving 26 selected brominated flamed retardants. Environ. Toxicol. Chem., 26: 816-826.

21. Orn, U. and E. Klasson-Wehler, 1998. Metabolism of 2,2',4,4'-tetrabromodiphenyl ether in rat and mouse. Xenobiotica, 28: 199-211.

22. Malmberg, T., M. Athanasiadou, G. Marsh, I. Brandt and A. Bergman, 2005. Identification of hydroxylated polybrominated diphenyl ether metabolites in blood plasma from polybrominated diphenyl ether exposed rats. Environ. Sci. Technol., 39: 5342-5348.

23. Marsh, G., M. Athanasiadou, I. Athanassiadis and A. Sandholm, 2006. Identification of hydroxylated metabolites in 2,2',4,4'-tetrabromodiphenyl ether exposed rats. Chemosphere, 63: 690-697.

24. Hakk, H., G. Larsen and E. Klasson-Wehler, 2002. Tissue disposition, excretion and metabolism of 2,2',4,4',5-pentabromodiphenyl ether (BDE-99) in the male Sprague-Dawley rat. Xenobiotica, 32: 369-382.

25. Chen, L.J., E.H. Lebetkin, J.M. Sanders and L.T. Burka, 2006. Metabolism and disposition of 2,2'4,4',5-pentabromodiphenyl ether (BDE99) following a single or repeated administration to rats or mice. Xenobiotica, 36: 515-534.

26. Hakk, H., J. Huwe, M. Low, D. Rutherford and G. Larsen, 2006. Tissue disposition, excretion and metabolism of 2,2'4,4',6-pentabromodiphenyl ether (BDE-100) in male Sprague-Dawley rats. Xenobiotica, 36: 79-94.

27. Benedict, R.T., H.M. Stapleton, R.L. Letcher and C.L. Mitchelmore, 2007. Debromination of polybrominated diphenyl ether-99 (BDE-99) in carp (Cyprinus carpio) microflora and microsomes. Chemosphere, 69: 987-993.

28. Marsh, G., R. Stenutz and A. Bergman, 2003. Synthesis of hydroxylated and methoxylated polybrominated diphenyl ethers - natural products and potential polybrominated diphenyl ether metabolites. Eur. J. Org. Chem., 2566-2576. 
29. Carlile, D.J., A.J. Stevens, E.I. Ashforth, D. Waghela and J.B. Houston, 1998. In vivo clearance of ethoxycoumarin and its prediction from in vitro systems. Drug Metab. Dispo., 26, 216-221.

30. da Silva, M.E.F. and N.C. Meirelles, 2004. Interaction of non-ionic surfactants with hepatic CYP in Prochilodus scrofa. Toxicol. In vitro, 18: 859-867.

31. Lewis, D.F.V, C. Ionnides and D.V. Parke, 1998. Cytochrome $\mathrm{P} 450$ and species differences in xenobiotic metabolism and activation of carcinogen. Environ. Health. Persp., 106: 633-641.

32. Chen, G.S. and N.J. Bunce, 2003. Polybrominated diphenyl ethers as Ah receptor agonists and antagonists. Toxicological Sci., 76: 310-320.
33. Eriksson, J., N. Gree, G. Marsh and A. Bergman, 2004. Photochemical decomposition of 15 polybrominated diphenyl ether congeners in methanol/water. Environ. Sci. Technol., 38: 3119-3125.

34. Braekevelt, E,. S.A. Tittlemier and G.T. Tomy, 2003. Direct measurement of octanol-water partition coefficients of some environmentally relevant brominated diphenyl ether congeners. Chemosphere, 51: 563-567.

35. Cotreau-Bibbo, M.M., L.L. Von Moltke and D.J. Greenblatt, 1996. Influence of polyethylene glycol and acetone on the in vitro biotransformation of tamoxifen and alprazolam by human liver microsomes. J. Pharm. Sci., 85: $1180-85$. 